\title{
Bilder der Chirurgie
}

Filme können sehr unterschiedlich rezipiert werden. Wie wahr diese Binsenweisheit ist, wurde mir kürzlich wieder bewusst, als ich innert 14 Stunden im Hinblick auf den bevorstehenden Westschweizer Kinostart zweimal «Le Théâtre des Opérations»* des französisch-schweizerischen Doppelbürgers Benoît Rossel «visionierte». Ab DVD im Heimkino, notabene, da ich weder in Solothurn, wo der 86minütige Dokumentarfilm im Rahmen der diesjährigen Filmtage gezeigt wurde, noch in Nyon, wo er 2007 anlässlich des Festivals «Visions du Réel» mit dem Prix Cinéma Suisse TSR ausgezeichnet worden war, zu den Zuschauern gehört hatte.

Rossel taucht mit seiner Kamera ein in die Welt der Chirurgie am Centre Hospitalier Universitaire Vaudois in Lausanne, besser bekannt unter dem Kürzel CHUV. Der eigentliche Protagonist des Films ist der Operationstrakt des Spitals, wenngleich der Regisseur mit der Dokumentation der ersten chirurgischen Erfahrungen eines jungen Assistenzarztes eine Art von rotem Faden durch sein Werk gezogen hat, an dem sich die Zuschauer orientieren können.

Handwerklich ist der Film ohne Zweifel hervorragend gemacht. Rossel erzeugt durch ein virtuoses Zusammenspiel von Kameraführung, Schnitt und Ton eine Stimmung, die in ihrer Intensität unter die Haut geht. Er vermittelt dem Zuschauer in sehr verdichteter Form - man könnte sie durchaus stilisiert nennen - ein Bild der Chirurgie. Sein Bild, ein sehr subjektives also, über dessen Gültigkeit sich trefflich diskutieren lässt. Zwar wird von der Faszination des Körpers gesprochen, vom Drang zum Heldentum, davon, dass der Chirurgenberuf etwas sehr Männliches habe. Die Persönlichkeit der (angehenden) Chirurgen, ihre Motive bleiben aber seltsam vage.

Es liegt eine bedrückende Schwere über den auf Hochglanz polierten Gängen, in denen Menschen mit durchwegs ernsten Gesichtern agieren. Natürlich ist dieser Eindruck nicht aus der Luft gegriffen, genausowenig wie die - ebenfalls grossartig ins Filmische übersetzte - Fragmentierungstendenz, die dem Chirurgischen innewohnt. Es gibt in der Tat Chirurgen, die dem Patienten vor sehr schwierigen Eingriffen bewusst nicht in die Augen schauen, um sich voll und ganz auf das erkrankte Organ konzentrieren

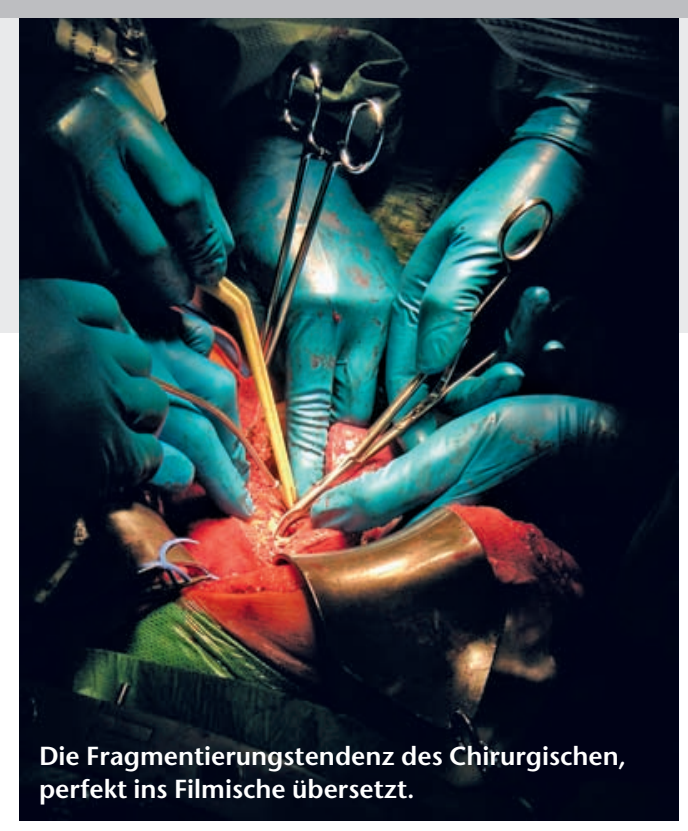

zu können. «La maladie doit rester technique», sagt denn auch einer der Ärzte im Film.

Und doch ist es nicht das volle Bild: In chirurgischen Abteilungen geht es im Berufsalltag auch oft sehr lustig zu und her, beispielsweise im Pausenzimmer zwischen zwei Operationen, nicht selten auch zwischen Chirurgen und ihren Patienten. Chirurgen finden - Gott weiss, wie sie das anstellen - Zeit, ihre vielfältigen Interessen zu pflegen und darüber zu diskutieren, seien diese kultureller, sportlicher oder auch kulinarischer Art. Solche Aspekte, die das volle Leben auch in einer chirurgischen Abteilung prägen, fehlen im Film, was ihm eine aseptisch-unwirkliche, mitunter etwas deprimierende Note gibt.

Wahrscheinlich liegt aber auch in diesem Fall alles - oder zumindest vieles - im Auge des Betrachters. Diese kritische Selbstreflexion drängte sich mir zumindest auf, als ich am Folgetag meiner Erstvisionierung von meinen Söhnen (Kindergarten- und Primarschulalter) genötigt wurde, ihnen den Film ebenfalls vorzuführen. Die Filmmusik, die sie am Vorabend im Bett mitbekommen hatten, liess sie einen Horrorfilm (und damit Hochspannung) vermuten. Und so war es denn auch: Nach dem Dokumentarfilm vom Samstagabend kam ich am Sonntagmorgen dank vier Kinderaugen in den Genuss eines Thrillers, um den Preis allerdings, dass ich gnadenlos über Details ausgequetscht wurde, die ich zuvor nicht einmal bewusst wahrgenommen hatte. Attribute wie «aseptisch-unwirklich» oder gar «deprimierend» waren nun plötzlich völlig fehl am Platz.

Fazit: Wer die Wahrheit über «Le Théâtre des Opérations» wissen will, kommt nicht darum herum, sich den Film selbst anzuschauen. Kinos. In der Deutschschweiz ist der Filmstart für den Herbst 2008 geplant.

Bruno Kesseli 